\title{
Being vaccinated for love or despite fear of vaccination? The influence of priming on vaccination intention among young French people
}

\section{BACKGROUND}

In France, despite fear-based communication by the authorities and the media, vaccination against COVID-19 has received little support from the population. For a young population often convinced that severe forms of the disease affect older people, we hypothesized that communication based on the idea of love would be more effective than communication based on fear of vaccination.

\section{PARTICIPANTS AND PROCEDURE}

In a convenience online French sample $\left(N=480, M_{\text {age }}=19.4\right)$, vaccination intention was asked after fear priming, love priming, no love/prejudice priming, or a control condition. Participants also reported their fear of vaccination against COVID-19, and the recommendation they would make regarding vaccination of a loved/unloved person.

RESULTS

Vaccination intention was higher in the love condition than in the fear and no love/prejudice conditions. Surprisingly,

\begin{abstract}
fear of vaccination was lower in participants who were pre-
\end{abstract} sented with fear-inducing questions.

\section{CONCLUSIONS}

Implications of these results are discussed in relation to the fear of vaccination and the transpersonal value of the idea of love. The results suggest that COVID-19 is experienced as a threat both to oneself and to those one loves most. Therefore, calls for fear in the media and on social networks seem less likely to motivate a young population to vaccinate than the reminder of intense emotional ties to loved ones.

\section{KEY WORDS}

love; fear of vaccination; COVID-19; vaccination intention

ORGANIZATION - 1: University of Paris, Paris, France $\cdot 2$ : Southern Brittany University, Lorient, France AUthors' Contributions - A: Study design - B: Data collection - C: Statistical analysis - D: Data interpretation .

E: Manuscript preparation · F: Literature search · G: Funds collection

CORRESPONDING AUthor - Prof. Lubomir Lamy, University of Paris, 143 Av. de Versailles, 75016 Paris, France, e-mail: lubomir.lamy@u-paris.fr 


\section{BACKGROUND}

Coronavirus 2019 (COVID-19) was first detected in December 2019 in the Chinese city of Wuhan. High levels of fear have emerged in relation to the pandemic nature of this disease, its relatively high mortality rate and its very high infection rate (Ahorsu et al., 2020; Lin, 2020). In addition, exposure to media news and discussions about the pandemic have exacerbated fear, psychological distress and anxiety (see Scopelliti et al., 2021, for a review). Fear appeals have been used worldwide. In France, since the end of February 2020, the population has been confronted with a daily reminder of threatening information, including: number of people hospitalized, number of patients in intensive care, number of beds still available in hospitals, number of new infections, number of deaths in the last 24 hours, total number of deaths. These figures have themselves often been compared with those of other countries, in Europe and elsewhere in the world, particularly when symbolic thresholds were crossed, e.g., when the world passed the one million dead mark of COVID-19 on September 29, 2020. The curves of the evolution of the pandemic have often been presented. There have been countless debates about the health crisis. The Director-General of Health and the Minister of Health have given numerous press conferences. The President of the Republic, Emmanuel Macron, addressing the French people on March 16, 2020, used the expression "We are at war" twelve times. In this anxiety-provoking context, the possibility of a future vaccine against COVID-19 was generally presented as the only favorable outcome to this health crisis.

The Regional Health Agencies, the Minister of Health and various doctors, heads of hospital departments and epidemiologists, invited to speak in the media, relayed to the general public the sanitary instructions intended to limit the spread of the epidemic, for example: social distancing, wearing of masks, limitation of social contacts, encouragement to vaccinate. The possibility of treating the disease with hydroxychloroquine was the subject of much controversy and was quickly banned in most cases. At the same time, the social networks carried numerous theses called "conspiracy theories" by their opponents, contesting the merits of vaccination and denouncing the financial and surveillance interests of the population, considered to be the real objectives of the vaccination campaign. The French population was thus confronted, schematically, with two antagonistic visions of the epidemic. An official message, conveyed by the traditional media, insisted on the absolute necessity of generalized vaccination. A contentious message, carried by social networks, challenged the official recommendations and proposed therapeutic alternatives to vaccination, or even no therapy at all when the very existence of the pandemic was in doubt.

\section{FEAR AND INTENTION CHANGE}

The question of the effectiveness of fear appeals in bringing about a change in attitude or behavior has been the subject of much research over the past 60 years, with often conflicting results. A recent meta-analysis, however, concluded on the overall effectiveness of fear appeals on attitudes, intentions, and behaviors (Tannenbaum et al., 2015). Specifically, "fear appeals were more effective when the message depicted relatively high amounts of fear, included an efficacy message, and stressed susceptibility and severity related to the concerns being addressed" (Tannebaum et al., 2015, p. 1196). These criteria seem a priori to apply to the context of the health crisis in France. The calls to fear were intense and repeated. They were coupled with the prospect of more than $90 \%$ effective vaccination for the first vaccines coming on the market (Pfizer, Moderna, Sputnik), i.e., they included an efficacy message. People were reminded of the chances of contracting COVID-19, emphasizing the high contagiousness of the virus. The risk of developing severe forms of the disease (severity criterion) was mostly associated with "vulnerable people", the elderly or those with co-morbidities, as opposed to young people or children, who were often presented as potentially asymptomatic.

Response efficacy and perceived self-efficacy appear as key predictors of the intention to engage in adaptive behavior (Floyd et al., 2000; Ruiter et al., 2001). Pharmaceutical companies and health authorities have communicated on the efficacy of new vaccines. This information, combined with fear of the disease, might plausibly have led to a favorable attitude towards vaccination. In France, this model has not been observed. A survey (IPSOS, 2020) conducted in December 2020, just before the vaccination campaign started in France, showed that among 15 industrialized countries, France had the lowest vaccination intention rate (40\%; USA 69\%; China 80\%). Moreover, vaccination intention in France was on a downward trend, from 59\% in August 2020 to 54\% in October and $40 \%$ in December. Hopes for the arrival of vaccines against COVID-19 were therefore accompanied by increasing reluctance among the French population. This reluctance is often expressed in the media and on social networks by a new fear. In addition to the fear of the disease, there is also the fear of new vaccines. Vaccines developed in an unusually short time raise questions about their reliability, as well as the lack of hindsight regarding their possible side effects.

\section{LOVE AND COVID-19}

The most frequently expressed reason for refusing to be vaccinated was concern about side effects $(72 \%$ of responses; IPSOS, 2020). Thus, it appears that the fear 
of COVID-19 combines, in France, with the fear of vaccination to produce the lowest rate of intention to vaccinate among the major industrialized countries. Acceptance of vaccination is nevertheless a major public health issue, accentuated at the time this study was carried out by the arrival in France of COVID-19 variants much more contagious than the original strain: British, South African and Brazilian variants.

Regardless of the reasons for not getting vaccinated, one must also ask the question about the reasons for getting vaccinated. Beyond concern for one's own health, an often stated reason for taking precautions and avoiding COVID-19 is the desire to protect loved ones. The most common case is that of grandchildren avoiding visiting their grandparents, whom they consider vulnerable. In this study, we hypothesized that the idea of love may overcome the fear of being vaccinated. To date, the relationship between fear and love has never been made explicit in the literature. In the absence of love in the sense given to it by human beings, we can recall that many animal species overcome their fear of a predator to protect their offspring. In the human species, beyond the defense of one's own family, one can think that acts of courage or heroism are underpinned by a strong altruistic motivation, i.e. by impersonal love. Past research has shown that love priming has an effect on helping behavior, and in particular on chivalrous helping (Lamy et al., 2009, 2010). In particular, it has been shown that men who were primed with the idea of love were more inclined than those in a control group to dare to confront a group of disreputable-looking male confederates in order to do a young woman a favor (Lamy et al., 2010). To our knowledge, however, no study has compared the influence of fear and love priming on behavioral intention. In the context of the start of the vaccination campaign in France, we made the following assumptions:

H1: Love priming, as compared to fear of vaccination priming, will trigger more vaccination intentions.

$\mathrm{H} 2$ : Love priming, as compared to the priming of a relational situation where love is lacking, will produce more vaccination intention. $\mathrm{H} 2$ is justified by the need to discard a possible confounding effect. The effect of love priming could be just the effect of any relational situation. Being infected by COVID-19 is itself relational in nature, since most transmission occurs during person-to-person contact. Thus, directing participants' attention to an interpersonal dimension could lead to greater sensitivity to the rules of social life, including health recommendations. However, we believe that the effect of love priming is not limited to its relational dimension.

H3: Past research has shown that emotional states are not exclusive of each other, but rather consist of overlapping experiences (Posner et al., 2005). Therefore, as an exploratory hypothesis we postulated that love priming would have no effect on the fear of being vaccinated.

\section{PARTICIPANTS AND PROCEDURE}

\section{PARTICIPANTS}

As young people are generally presented by the media as less at risk of developing severe forms of the disease, but as contagious as the rest of the population, it seemed to us that the stakes of vaccination are higher for this population, which is a priori less willing to be vaccinated. Therefore, we chose to limit our focus to a population aged 16 to 30 years. Participants $\left(N=480,71 \%\right.$ women, $\left.M_{\text {age }}=19.40, S D_{\text {age }}=2.70\right)$ were contacted on social networks to anonymously complete an online questionnaire.

\section{PROCEDURE}

In this cross-sectional study, participants were randomly assigned to receive the link to one out of four questionnaires corresponding to the four experimental conditions: fear of vaccination, love, prejudice, or control (see Figure 1).

In the control condition, participants answered the question, "Do you intend to get vaccinated against COVID-19?" (yes/no), and then indicated their gender and age. The wording of the vaccine intention question maximizes the ecological validity of this measure. After a year or so of intense discussion about the upcoming introduction of vaccines, we estimated that most participants would have arrived at a behavioral decision: accept or reject the vaccine. In the fear of vaccination condition, participants were first asked two questions reflecting uncertainty about

\section{Figure 1}

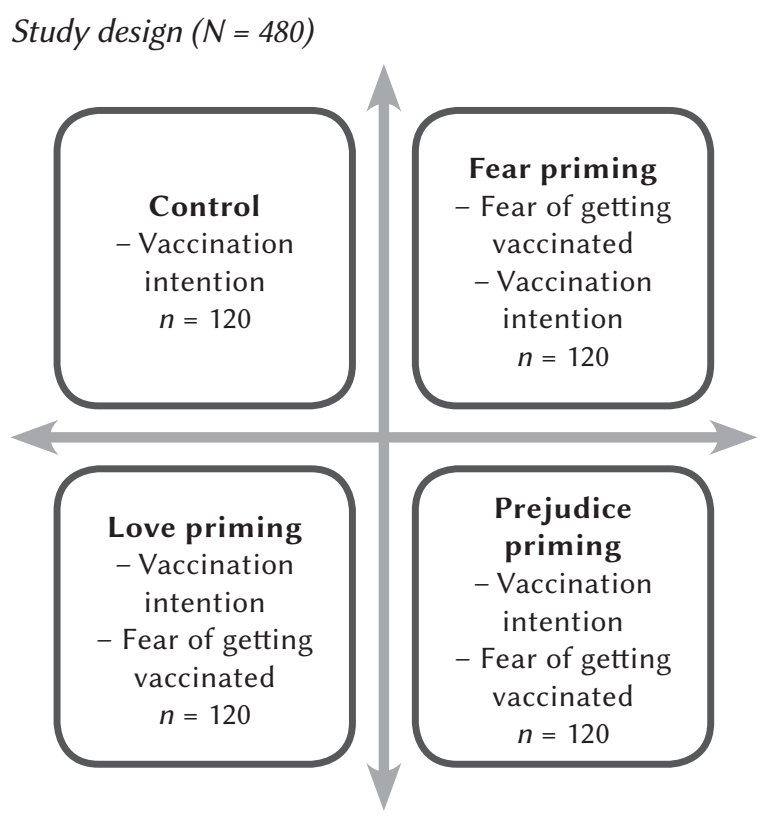

Love and fear of vaccination 
Lubomir Lamy, Jérôme Guegan, Jacques

Fischer-Lokou, Nicolas Guéguen
COVID-19 vaccines: "Do you feel that the vaccines already available against COVID-19 are sufficiently reliable in terms of treatment?" (7-point scale ranging from 1 - strongly disagree to 7 - strongly agree); "Health authorities consider the so-called 'messenger RNA' technique used in the vaccines already available to be 'safe enough' and not likely to alter the recipient's genome. What is your personal opinion? Is it a scientific advance or a potentially dangerous scientific advance?" (7-point scale ranging from 1 - a scientific advance to 7 - a potentially dangerous scientific advance). Next, participants responded to a multiple-choice question about their fear of getting vaccinated, "Do you feel any fear about getting the COVID-19 vaccine?" (1 - not at all, 7 - intensely). Finally, participants answered the same questions as in the control group: vaccination intention, gender, age. In the love condition, the five initial questions were designed to get participants to recall a loved one: "Can you recall the person you have loved most in your life? When you recall his or her features, his or her physical appearance, is that image rather accurate and vivid, or rather blurry and unreal?" (1 - accurate and vivid, 7 - blurred and unreal); "How intensely did you love - or do you love - this person?" $(1$ - weakly, 7 - intensely); "Would you say that this person is a part of you?" (1 - not at all, 7 - complete$l y$ ); "Do you feel that this love will always be a part of you?" (1 - not at all, 7 - completely); "The person you have been thinking about since the beginning of this questionnaire, the one you have loved the most in your life, would you recommend them to be vaccinated against COVID-19?" (yes/no). Next, participants

\section{Figure 2}

\section{Percentage intending to be vaccinated according to experimental condition $(N=480)$}

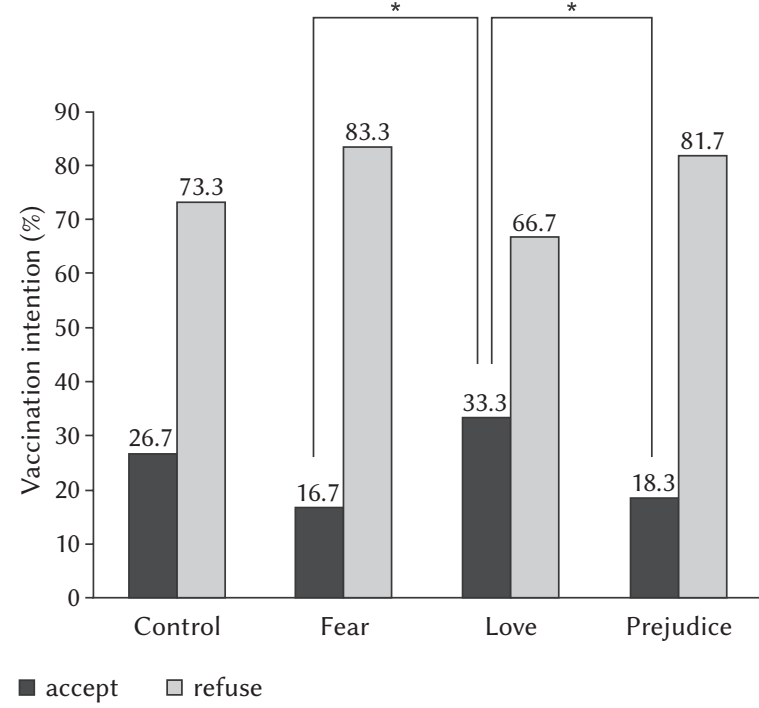

Note. Statistically significant differences are indicated $\left(^{*}\right)(p \leq .01)$ were asked about their intention to be vaccinated, their fear of vaccination, and finally indicated their gender and age. In the prejudice condition, the questionnaire used was identical to the one used in the love condition, with one notable difference: the first five questions, instead of referring to the person they loved the most, dealt with the person who harmed them the most ("Can you remember the person who harmed you the most during your life?"). Once a participant had finished answering the assigned questionnaire and had clicked on the "submit" button, the corresponding data were automatically imported into a Google Sheets spreadsheet. All responses obtained were retained, with the exception of those participants under the age of 16 or over the age of 30 . In this study, age was the only exclusion criterion. The study was approved by the local Institutional Review Board (decision 07012021-2). The analysis was conducted using the SPSS statistical software package.

\section{RESULTS}

In this study, the dependent variable was whether participants reported that they intended to get vaccinated. There was no gender difference regarding vaccination intention. Among women, 81 of 341 (23.8\%) reported their intention to get vaccinated, as compared to 33 of 138 (23.9\%) among men, so their data were collapsed. Overall, 114 of 480 participants said they wanted to be vaccinated $(23.8 \%)$. A 4 (experimental condition) $\times 2$ (participant gender) log-linear analysis was performed, with the frequency of participants who intended to get vaccinated as the dependent variable. The main effect of experimental condition was statistically significant (see Figure 2), $\chi^{2}(3,480)=11.57, p<.001$, Cramer's $V=.15$. The main effect of gender was not statistically significant, $\chi^{2}(1,480)=0.23, p=.631$, and no interaction effect was found. Additional analyses revealed that participants in the love condition were more willing to get vaccinated than in the fear condition $\left(\chi^{2}(1,240)=8.89, p=.003, \Phi=.19, \mathrm{RR}=2.00\right)$ or the prejudice condition $\left(\chi^{2}(1,240)=7.05, p=.008, \Phi=.17\right.$, $\mathrm{RR}=1.82)$. Vaccination intention in the control group was not significantly different, as compared to the love $\left(\chi^{2}(1,240)=1.27\right.$, n.s. $)$ or prejudice conditions $\left(\chi^{2}(1,240)=2.39\right.$, n.s. $)$. Vaccination intention in the control group was marginally higher than in the fear condition $\left(\chi^{2}(1,240)=3.54, p=.060, \Phi=.12, \mathrm{RR}=0.62\right)$.

As compared to the fear condition, the fear of getting vaccinated was higher in the love condition $(t(238)=3.41, p=.002$, Cohen's $d=.47)$ and in the prejudice condition $(t(238)=5.55, p<.001$, Cohen's $d=.77$ ); see Table 1 . It also appeared that participants who did not plan to vaccinate were more afraid of vaccination than those who planned to vaccinate $(t(358)=6.24, p<.001$, Cohen's $d=.78)$. 
Table 1

Fear of vaccination according to experimental condition (mean and standard deviation)

\begin{tabular}{lcccc}
\hline & Fear & Love & Prejudice & Total \\
\hline Vaccination willingness & $1.95_{\mathrm{a}}(0.88)$ & $3.00_{\mathrm{b}}(1.78)$ & $3.68_{\mathrm{c}}(1.91)$ & $2.93_{\mathrm{i}}(1.75)$ \\
No vaccination willingness & $3.60_{\mathrm{d}}(1.19)$ & $4.72_{\mathrm{e}}(2.03)$ & $4.89_{\mathrm{e}}(2.08)$ & $4.38_{\mathrm{j}}(1.88)$ \\
Total & $3.33_{\mathrm{f}}(1.30)$ & $4.15_{\mathrm{g}}(2.11)$ & $4.67_{\mathrm{h}}(2.10)$ & $4.05(1.95)$ \\
\hline
\end{tabular}

Note. Means differ at $p \leq .01$ (subscripts ac, fg, ce) or $p<.001$ (subscripts de, ad, be, fh, ij), or they do not differ significantly.

In the love condition, a positive correlation appeared between the fear of being vaccinated and two of the relational items, namely the one about the intensity of love (Pearson's $r=.24, p=.007$ ) and the one indicating that the loved one is considered a part of ourselves (Pearson's $r=.26, p=.004$ ). In the prejudice condition, no correlation was observed between fear of being vaccinated and relational items. Finally, we found a strong association between the intention to get vaccinated and the recommendation we would make to another person. In the love condition, $91.3 \%$ (73 of 80) of those who did not want to get vaccinated declared they would recommend to someone they love not to get vaccinated either; $82.5 \%$ (33 of 40) of those who intended to get vaccinated said they would recommend the person they love to also get vaccinated $\left(\chi^{2}(1,120)=65.30, p<.001, \Phi=.73\right)$. In the prejudice condition, these figures were $67.3 \%$ (66 of 98) and $72.7 \%(16$ of 22$)$, respectively $\left(\chi^{2}(1,120)=12.00\right.$, $p<.001, \Phi=.31)$.

\section{DISCUSSION}

The present study explored the influence of fear of vaccination priming, love priming, and non-love/prejudice priming on the intention to receive a COVID-19 vaccine. As anticipated (H1), participants primed with the idea of love demonstrated an increased intention to be vaccinated, as compared to participants primed with fear-inducing content. We also confirmed (H2) that participants primed with the idea of love showed an increased intention to get vaccinated, as compared to participants primed with the idea of a relationship that caused them prejudice. Concerning hypothesis $\mathrm{H} 3$, we anticipated that love priming would not affect fear of vaccination. Our results are consistent with this, despite a marginal decrease in fear in the love condition, as opposed to the prejudice condition. However, we obtained an unanticipated result: the level of fear was much lower in the fear condition than in the love and prejudice conditions. It may seem paradoxical that fear of vaccination was lower in participants who were presented with fear-inducing questions. Yet this response pattern is consistent with past research showing that fear arousal is unlikely to elicit self-protective behavior in those who feel vulnerable (Breakwell \& Jaspal, 2021). Fear control processes may result in people engaging in denial and avoidance, so as to minimize fear (Ruiter et al., 2001; Roskos-Ewoldsen et al., 2004). In the present case, fear priming may have reactivated a defensive reaction against the ambient fear that had been constantly renewed for almost a year. The pattern of results we obtained, with lower vaccine fear and vaccine intention when vaccine fear, as compared to love, was suggested, further indicates that a high level of vaccine fear is not necessarily related to low vaccine intention, as one might have intuitively thought.Unlike previous research that has found threat and prosocial messages to be equally effective in fostering intentions to engage in prevention behaviors against COVID-19 (Heffner et al., 2021; Jordan et al., 2020), we found that love priming was more effective than fear in inducing an intention to vaccinate. One possible explanation for this discrepancy is that prosocial motivation is not underpinned by a connection to any known and loved person. For example, the statement: "Together, by selfisolating we can save millions of lives" (Heffner et al., 2020 , p. 3) is based on the abstract concept of love of humanity, without evoking a particular loved figure. Future research should confirm that the love of one person, who matters a great deal to us, is a more powerful lever for changing behavior than the abstract concern for many. These conclusions must be qualified, however, by recalling that the procedure implemented in this study is relatively specific. Contrary to the usual pattern of fear appeal studies, here we did not highlight a danger (the disease) with an effective remedy (the vaccine). Instead, we asked three questions that might question the appropriateness of this remedy. This procedure can be considered as giving free rein to, or even accentuating, an already widespread ambient fear. Future research should therefore confirm that the classic fear appeal scheme induces results comparable to those obtained here.

Our results, however, suggest that calls for fear in the media and on social networks are much less likely to motivate a young population to vaccinate than the reminder of intense emotional ties to loved ones. Fur- 
Lubomir Lamy,

Jérôme Guegan, Jacques

Fischer-Lokou, Nicolas Guéguen thermore, the result observed in the prejudice condition showed that priming the idea of relationality is not sufficient to increase vaccination intention. The idea of a "we" specific to love could explain at least in part: a) that participants in the love condition closely matched their vaccination intention with their advice to their loved one, b) that their level of fear correlated with the intensity of their loving relationship and the impression that this love was part of themselves. This pattern of results might suggest that COVID-19 is experienced as a threat both to oneself and to those one loves most, and that vaccination is a way to protect those one loves as much as to protect oneself. And to achieve this end, fear can be overcome, unlike the prejudice condition where fear is also high but intent to vaccinate is low, and the fear condition where fear is rejected, and with it the protective measure of vaccination.

The main limitation of this study is that behavioral intention was measured, not actual behavior. An overview of research on the intention-behavior gap concluded that "intentions get translated into action approximately one-half of the time" (Sheeran \& Webb, 2016, p. 511). In addition, when comparing the fear and love conditions, we obtained a small-to-medium effect size. However, vaccination against COVID-19 is such a major public health issue that even a modest increase in actual vaccinations cannot be overlooked. Moreover, the present study focused on a young population, which in France is both the most reluctant to be vaccinated and the most at risk of unprotected informal gatherings, likely to spread the virus. Therefore, our results, if confirmed by other studies, should be used in vaccination awareness campaigns. With a young audience, the constant appeal to fear is probably less effective than a reminder of the bonds of love.

Future research should also explore the possible effects of the other aspect of fear, namely, fear of the disease itself. Reminding people of the dangers of the disease could lead to a desire to protect oneself from it through vaccination, or it could be a defensive reaction against an overly intrusive fear, to the detriment of one's health.

\section{RefERENCES}

Ahorsu, D. K., Lin, C. Y., Imani, V., Saffari, M., Griffiths, M. D., \& Pakpour, A. H. (2020). The fear of COVID-19 Scale: Development and initial validation. International Journal of Mental Health and Addiction. https://doi.org/10.1007/s11469-020-00270-8

Breakwell, G. M., \& Jaspal, R. (2021). Identity change, uncertainty and mistrust in relation to fear and risk of COVID-19. Journal of Risk Research, 24, 335-351. https://doi.org/10.1080/13669877.2020.1864011

Floyd, D. L., Prentice-Dunn, S., \& Rogers, R. W. (2000). A meta-analysis of research on protection motiva- tion theory. Journal of Applied Social Psychology, 30, 407-429. https://doi.org/10.1111/j.1559-1816.2000. tb02323.x

Heffner, J., Vives, M. L., \& Feldman Hall, O. (2021). Emotional responses to prosocial messages increase willingness to self-isolate during the COVID-19 pandemic. Personality and Individual Differences, 170, 110420. https://doi.org/10.1016/j.paid.2020.110420

IPSOS (2020). Global attitudes on a COVID-19 vaccine. Retrieved from https://www.ipsos.com/sites/ default/files/ct/news/documents/2020-12/globalattitudes-on-a-covid-19-vaccine-december-2020report.pdf [accessed February 23, 2021]

Jordan, J., Yoeli, E., \& Rand, D. (2020, April 3). Don't get it or don't spread it: Comparing self-interested versus prosocial motivations for COVID-19 prevention behaviors. PsyArXiv. https://doi.org/10.31234/ osf.io/yuq7x

Lamy, L., Fischer-Lokou, J., \& Guéguen, N. (2009). Induced reminiscence of love and chivalrous helping. Current Psychology, 28, 202-209. https://doi. org/10.1007/s12144-009-9059-9

Lamy, L., Fischer-Lokou, J., \& Guéguen, N. (2010). Valentine street promotes chivalrous helping. Swiss Journal of Psychology, 69, 167-170. https://doi. org/10.1024/1421-0185/a000019

Lin, C. Y. (2020). Social reaction toward the 2019 novel coronavirus (COVID-19). Social Health and Behavior, 3, 1-2. https://doi.org/10.4103/SHB.SHB_11_20

Posner, J., Russell, J. A., \& Peterson, B. S. (2005). The circumplex model of affect: an integrative approach to affective neuroscience, cognitive development, and psychopathology. Development and Psychopathology, 17, 715-734. https://doi.org/ 10.1017/S0954579405050340

Roskos-Ewoldsen, D. R., Yu, J., \& Rhodes, N. (2004). Fear appeal messages affect accessibility of attitudes toward the threat and adaptive behaviors. Communication Monographs, 71, 49-69. https://doi. org/10.1080/0363452042000228559

Ruiter, R. A. C., Abraham, C., \& Kok, G. (2001). Scary warnings and rational precautions: a review of the psychology of fear appeals. Psychology and Health, 16, 613-630. https://doi.org/10.1080/ 08870440108405863

Scopelliti, M., Pacilli, M. G., \& Aquino, A. (2021). TV news and COVID-19: Media influence on healthy behavior in public spaces. International Journal of Environmental Research and Public Health, 18, 1879. https://doi.org/10.3390/ijerph18041879

Sheeran, P., \& Webb, T. L. (2016). The intention-behavior gap. Social and Personality Psychology Compass, 10, 503-518. https://doi.org/10.1111/spc3.12265

Tannenbaum, M. B., Hepler, J., Zimmerman, R. S., Saul, L., Jacobs, S., Wilson, K., \& Albarracín, D. (2015). Appealing to fear: a meta-analysis of fear appeal effectiveness and theories. Psychological Bulletin, 141, 1178-1204. https://doi.org/10.1037/a0039729 